Check for updates

Cite this: RSC Adv., 2017, 7, 22280

Received 2nd December 2016

Accepted 7th April 2017

DOI: 10.1039/c6ra27693h

rsc.li/rsc-advances

\section{Preparation of a colon-specific sustained-release capsule with curcumin-loaded SMEDDS alginate beads}

\author{
Yuxia Zhang, ${ }^{a}$ Yan Bai, ${ }^{a}$ Huali Chen, ${ }^{a}$ Yuanrui Huang, ${ }^{\mathrm{b}}$ Pei Yuan ${ }^{\mathrm{a}}$ \\ and Liangke Zhang $\mathbb{D}$ *a
}

A colon-specific capsule with alginate beads containing a self-microemulsifying drug delivery system (SMEDDS) was developed and evaluated. The SMEDDS technique was used to improve the solubility of curcumin (Cur). After encapsulating the Cur-loaded SMEDDS, the alginate beads were placed inside an impermeable capsule body. A konjac glucomannan/lactose/hydroxypropyl methylcellulose (KG/Lac/ HPMC) plug tablet was then prepared and placed in the mouth of the capsule. The capsule demonstrated a pulsatile drug-release profile with a specific lag time and subsequent sustained-release phase. The lag time was modified by changing the type of HPMC and the ratio of KG/Lac/HPMC. In addition, $0.5 \% \beta$-mannase solution and $5 \%$ rat cecal solution were used to simulate the colon fluid, significantly decreasing the lag time of the capsule. The results show that the capsule has potential for use in colon-specific drug delivery and exhibits a sustained-release characteristic.

\section{Introduction}

Colon-specific drug delivery systems have attracted increasing attention in recent years. To date, substantial effort has been devoted to the development of enzyme-triggered delivery systems because of their strong specificity, good biocompatibility, and accurate and reliable drug release., ${ }^{1,2}$ Recently, a pulsatile capsule drug delivery system that consists of a waterinsoluble capsule body filled with drugs and a plug tablet positioned at the mouth of the capsule has been developed. ${ }^{3,4}$ The lag time of the drug release is mainly determined by the erosion property of the plug tablet. This system has been used to deliver 5-aminosalicylic acid, a water-soluble drug, to the colon. $^{5}$ However, it is difficult for water-insoluble drugs to release completely in the colon because the amount of colonic fluid is less than the amount of gastric juice and small intestine fluid. ${ }^{6}$

In recent years, self-microemulsifying drug delivery systems (SMEDDSs) have been developed to increase the solubility and bioavailability of hydrophobic drugs. ${ }^{7,8}$ An SMEDDS is a monophasic liquid preparation composed of oil, surfactant, cosurfactant, and drug. However, liquid SMEDDSs are unstable, inconvenient, and have limited dosage preparations. ${ }^{9}$ To overcome these problems, an increasing number of researchers are

${ }^{a}$ Chongqing Key Laboratory of Biochemistry and Molecular Pharmacology, Chongqing Research Center for Pharmaceutical Engineering, College of Pharmacy, Chongqing Medical University, District of Yuzhong, Chongqing 400016, P. R. China. E-mail: zlkdyx@126.com; Fax:+86-23-6848-5161; Tel: +86-23-6848-5161

${ }^{b}$ Department of Pharmacy, Banan Hospital of TCM, Chongqing 400010, P. R. China focusing on the development of solid SMEDDSs (SSMEDDSs) ${ }^{10-12}$ in which liquid SMEDDSs are processed into powders, granules, pellets, tablets, or solid dispersions to improve patient compliance and commercial potential. ${ }^{13,14}$

Curcumin (Cur) is a natural polyphenol extracted from Curcuma longa L. and exhibits anticancer and antiinflammatory properties. ${ }^{15-18}$ Current studies indicate that Cur can inhibit the proliferation of colon cancer cells and effectively mitigate ulcerative colitis. ${ }^{19}$ However, the clinical application of Cur is limited by its low oral bioavailability, which is caused by poor water solubility. Moreover, Cur has a short half-life and less active metabolites. Thus, delivery systems that can improve Cur solubility and achieve sustained drug release are highly valuable. SMEDDS technology has been used to improve Cur solubility and bioavailability. ${ }^{20}$

Natural polysaccharides have received increasing attention in drug delivery systems because they exhibit nontoxicity, good biocompatibility, and adjustable controlled release properties. ${ }^{21,22}$ Konjac glucomannan (KG), a high-molecular-weight polysaccharide, is a promising novel material for colonspecific drug delivery systems; while it is resistant to the digestive enzymes in the upper gastrointestinal tract, it can be degraded by colonic microbial enzymes., ${ }^{5,23,24}$ Therefore, the present study aims to investigate the applicability of a delivery system that can deliver Cur to the colon using a colon-specific capsule with a KG-containing plug.

In the present study, a Cur-loaded SMEDDS (Cur-SMEDDS) was prepared and incorporated into calcium alginate beads (Cur-SMEDDS-CABs) to construct an S-SMEDDS. The resultant Cur-SMEDDS-CABs were placed into the bottom of an 
impermeable capsule with a KG/lactose/hydroxypropyl methylcellulose (KG/Lac/HPMC) plug tablet in its mouth. The formulation of the plug tablet was optimized, and the properties of the Cur-SMEDDS-CABs were evaluated. The factors affecting the lag time of the capsule were investigated to determine the mechanism of drug release.

\section{Experimental}

\section{Materials and animals}

The following materials were purchased from commercial providers and used as received: Cur (98\%, Aladdin, China), ethyl oleate (Tianjin Guangfu Chemical Co., China), sodium alginate (ALG, FMC Co., USA), Transcutol P (Gattefosse Co., France), Cremophor RH40 (BASF Co., Germany), enteric and gelatin capsules (size 0, Guangzhou Chaozhou Co., Ltd., China), ethyl cellulose (Shanghai Colorcon Co., Ltd., China), konjac glucomannan (KG, Chongqing Limao Agricultural Products Development Co., Ltd., China), hydroxypropyl methylcellulose (HPMC, Methocel® K15M, K4M, E50-LV grade, Shanghai Colorcon Co., Ltd., China), lactose (Lac, Granulac ${ }^{\circledR}$ 200, Meggle Co., Germany), talcum powder (Anhui Shanhe Pharmaceutical Excipients Co., Ltd., China), $\beta$ mannase (Kunming Qactive Biotechnology Co., Ltd., China). All other reagents were of analytical grade. Male and female SpragueDawley rats with weights ranging between 200 and $250 \mathrm{~g}$ were provided by Chongqing Medical University Animal Experiment Center and housed in standard specific pathogen-free (SPF) environmental conditions. The animal experiments were approved by the Animal Ethics Committee of Chongqing Medical University (Chongqing, China).

\section{Preparation of impermeable capsule bodies}

The caps and bodies of the gelatin capsules were separated manually. The gelatin capsule bodies were made into impermeable capsule bodies through the filling method. Dichloromethane, anhydrous ethanol, and ethyl acetate were mixed at a ratio of $4: 0.8: 0.2(\mathrm{v} / \mathrm{v})$. Ethyl cellulose was dissolved in the mixed solution to obtain an ethyl cellulose concentration of $120 \mathrm{~g} \mathrm{~L}^{-1}$. The resulting solution was placed inside the gelatin capsules (size 0) without caps in a capsule board. The board was immediately refrigerated at $4{ }^{\circ} \mathrm{C}$ for $24 \mathrm{~h}$ to volatilize the solvent. Finally, the capsules were placed in water to remove the gelatin. The impermeable capsule bodies (Fig. 1a) were prepared as described above.

\section{Preparation of Cur-SMEDDS-CABs}

Transcutol P, ethyl oleate, and Cremophor RH40 were mixed at a ratio of $0.175: 0.3: 0.525(\mathrm{w} / \mathrm{w})$ under magnetic stirring (200 $\mathrm{rpm}$ ) and then immersed in a thermostatic water bath at $37^{\circ} \mathrm{C}$ for $10 \mathrm{~min}$ to obtain the blank SMEDDS. A clear Cur-SMEDDS was prepared by mixing $60 \mathrm{mg}$ of Cur and $1 \mathrm{~g}$ of blank SMEDDS. The mixture was stirred at $37{ }^{\circ} \mathrm{C}$ for $0.5 \mathrm{~h}$. CurSMEDDS solution ( $0.6 \mathrm{~g})$ was added to $2 \mathrm{~mL}$ of sodium alginate solution $(3 \%, \mathrm{w} / \mathrm{v})$, and the resulting mixture was stirred (200 rpm) at room temperature until a clear yellow solution was obtained. The liquid was added dropwise into $\mathrm{CaCl}_{2}$ solution $(4 \%, w / v)$ through a fine six-gauge stainless-steel needle with an

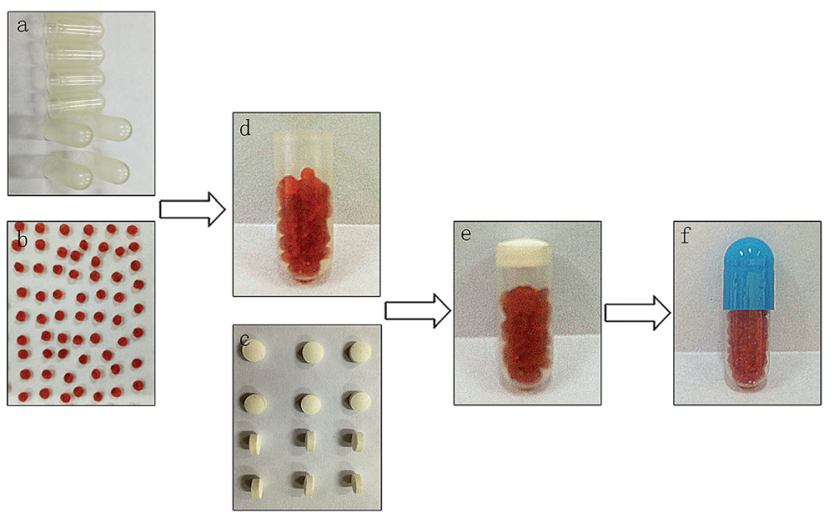

Fig. 1 Assembly of colon-specific plug-controlled capsule delivery system with Cur-SMEDDS-CABs. (a) Impermeable capsule body. (b) Cur-SMEDDS-CABs. (c) Plug tablet. (d) Cur-SMEDDS-CABs in impermeable capsule body. (e) Capsule without enteric cap. (f) Completed plug capsule.

inner diameter of $0.4 \mathrm{~mm}$. The distance from the needle to the surface of the $\mathrm{CaCl}_{2}$ solution was $8 \mathrm{~cm}$. The resultant solution was stirred slowly (50 rpm) for $1 \mathrm{~h}$ at room temperature. The Cur-SMEDDS-CABs were filtered and washed thrice with distilled water. The Cur-SMEDDS-CABs were then dried at $45{ }^{\circ} \mathrm{C}$ for $3.5 \mathrm{~h}$ (Fig. 1b).

\section{Preparation of plug tablets}

KG, Lac, and HPMC were sieved through a $180 \mu \mathrm{m}$ sieve and then mixed in a mortar for $10 \mathrm{~min}$. Afterward, 1\% talcum powder was added, and the mixture was stirred for $10 \mathrm{~min}$. The final blends were pressed into plug tablets with diameters of 6 mm (Fig. 1c) by direct compression using a single-punch tablet press with shallow and concave punches (Jiangsu Taizhou Liming Pharmaceutical Machinery Co., China). The weight of each plug tablet was $100 \mathrm{mg}$, and the hardness of the tablet was controlled at $50 \mathrm{~N}$. In this study, plug tablets with different ratios of $\mathrm{KG} / \mathrm{Lac} / \mathrm{HPMC}(5: 4: 1,6: 3: 1,7: 2: 1$ or $8: 1: 1)$ were prepared as described above.

\section{Assembly of the plug capsule}

The plug capsule was assembled through the following procedure. First, the Cur-SMEDDS-CABs were placed at the bottom of the impermeable capsule body (Fig. 1d). Second, the plug tablet was inserted into the impermeable capsule and located at the open end of the capsule body (Fig. 1e). Finally, the capsule body was enclosed with an enteric cap, and the joint between the capsule body and the enteric cap was sealed with a small amount of $8 \%$ ethyl cellulose solution (Fig. 1f).

\section{Differential scanning calorimetry (DSC) of the Cur-SMEDDS- CABs}

Samples of the pure drug (Cur), blank SMEDDS, blank beads, Cur-SMEDDS, and Cur-SMEDDS-CABs were placed in an aluminum pan and then heated from $100{ }^{\circ} \mathrm{C}$ to $300{ }^{\circ} \mathrm{C}$ at a constant rate of $10{ }^{\circ} \mathrm{C} \mathrm{min}$ min $^{-1}$ and at an air speed of $40 \mathrm{~mL}$ $\min ^{-1}$ in nitrogen atmosphere. The thermograms were 
obtained using a Netzsch STA449C thermal analyzer (Netzsch Corporation, Germany).

\section{Encapsulation efficiency (EE) determination}

Cur-SMEDDS-CABs (30 mg) were crushed and extracted with anhydrous ethanol. The resulting extract was stirred for $12 \mathrm{~h}$ and centrifuged at $4000 \mathrm{rpm}$ for $30 \mathrm{~min}$. The concentration of Cur in the supernatant was determined using a UV-vis spectrophotometer (Shanghai Unico instrument Co., Ltd., China). The EE was calculated as follows:

$$
\mathrm{EE} \%=\mathrm{TC} / \mathrm{TA} \times 100,
$$

where TC stands for the drug loaded in the Cur-SMEDDS-CABs, and TA represents the amount of drug dissolved in alginate solution.

\section{Determination of globule size of the Cur-SMEDDS-CABs}

The Cur-SMEDDS-CABs (30 mg) were pulverized and then placed in $10 \mathrm{~mL}$ distilled water. The resulting solution was vortexed for $5 \mathrm{~min}$ in a vortex mixer in the dark and filtered through a $0.22 \mu \mathrm{m}$ filter membrane. The average globule size of the microemulsion from the Cur-SMEDDS-CABs was determined at $25{ }^{\circ} \mathrm{C}$ using a Malvern Zetasizer (Nano-ZS, Malvern Instruments, UK). The size of the Cur-SMEDDS was also evaluated as described above.

\section{In vitro drug release studies}

In vitro drug release studies of the Cur-SMEDDS-CABs (Fig. 1b), Cur-SMEDDS-CABs in the impermeable capsule bodies without plug tablets and caps (Fig. 1d), Cur-SMEDDS-CABs in the impermeable capsule bodies with plug tablets (Fig. 1e), and the completed plug capsules (Fig. 1f) were performed in a shaking water bath (SHZ-88, Jiangshu Taichang Co., Ltd., China) at $37^{\circ} \mathrm{C}$ $\pm 0.5{ }^{\circ} \mathrm{C}$ and 100 times per min. In this study, $100 \mathrm{~mL}$ of aqueous release media including $\mathrm{HCl}$ solution with a $\mathrm{pH}$ of 1.2, phosphate buffer solution with a pH of 6.8 (PBS 6.8), 0.5\% (w/v) $\beta$-mannase in acetic acid-sodium acetate buffer solution with a $\mathrm{pH}$ of 6.0 , and $5 \%(\mathrm{w} / \mathrm{v})$ rat cecal solution with a $\mathrm{pH}$ of 7.4 were used. The $5 \%$ rat cecal solution was prepared by the method described by Liu et al. ${ }^{5}$ In brief, after being fed with $5 \% \mathrm{KG}$ solution at $3 \mathrm{~mL}$ per day for a week, the rats were sacrificed, and their cecal content was suspended in the simulated colonic solution, which consisted of $2 \mathrm{mmol} \mathrm{Na} \mathrm{HPO}_{4} \cdot 12 \mathrm{H}_{2} \mathrm{O}, 1 \mathrm{mmol}$ $\mathrm{NaHCO}_{3}, 0.8 \mathrm{mmol} \mathrm{NaCl}, 0.04 \mathrm{mmol} \mathrm{MgCl} \cdot 6 \mathrm{H}_{2} \mathrm{O}, 0.05 \mathrm{mmol}$ $\mathrm{CaCl}_{2} \cdot 2 \mathrm{H}_{2} \mathrm{O}, 0.6 \mathrm{mmol} \mathrm{KCl}$, and $0.05 \mathrm{mmol} \mathrm{CaCl}_{2} \cdot 2 \mathrm{H}_{2} \mathrm{O}$ in 100 $\mathrm{mL}$ of water. All experimental procedures were approved by the Institutional Animal Care and Use Committee of Chongqing Medical University (Chongqing, China).

At predetermined intervals, $5 \mathrm{~mL}$ of the release media was removed, collected, and replaced by fresh solution. The samples were centrifuged at $4000 \mathrm{rpm}$ for $10 \mathrm{~min}$. The supernatant (1 $\mathrm{mL})$ and anhydrous ethanol $(1 \mathrm{~mL})$ were then placed in a $5 \mathrm{~mL}$ brown volumetric flask, and the remaining volume was filled with $50 \%$ ethanol. The drug concentration was determined by measuring the absorbance using a UV-vis spectrophotometer
(Shanghai Unico instrument Co., Ltd., China). The wavelengths measured for PBS 6.8, 0.5\% $\beta$-mannase in acetic acid-sodium acetate buffer solution, and 5\% rat cecal solution were 424, 425, and $422 \mathrm{~nm}$, respectively. The data are given as the mean of three independent measurements.

\section{Results}

DSC

The thermograms of the pure drug (Cur), blank SMEDDS, blank alginate beads, Cur-SMEDDS, and Cur-SMEDDS-CABs are shown in Fig. 2. The pure drug showed a clear endothermic peak near $179{ }^{\circ} \mathrm{C}$, which is the melting point of Cur. The blank SMEDDS, blank beads, Cur-SMEDDS, and Cur-SMEDDS-CABs did not reveal any obvious peak near $179{ }^{\circ} \mathrm{C}$, indicating that the Cur was dispersed in the Cur-SMEDDS-CABs and CurSMEDDS in an amorphous state.

\section{Bead size, globule size, zeta potential and encapsulation efficiency of the Cur-SMEDDS-CABs}

The sizes of beads were measured with a Vernier caliper. All the beads had similar sizes, and the mean size was approximately $1.20 \pm 0.10 \mathrm{~mm}(n=50)$. The SMEDDS produced a transparent microemulsion with a globule size of less than $100 \mathrm{~nm}$ and provided a large interfacial surface area. The globule size of the Cur-SMEDDS-CABs was $79.6 \pm 0.5 \mathrm{~nm}$, which is larger than that of the Cur-SMEDDS $(31.1 \pm 0.3 \mathrm{~nm})$. It is possible that small amounts of oil, surfactant, or cosurfactant were retained in the alginate beads, which slightly changed the formulation of the Cur-SMEDDS. After being incorporated into the alginate beads, the Cur-SMEDDS-CABs could still form a microemulsion with a globule size less than $100 \mathrm{~nm}$. The EE of the Cur-SMEDDSCABs was determined to be $98.11 \% \pm 1.87 \%$, indicating that almost all Cur-SMEDDSs were encapsulated in alginate beads.

\section{Effects of impermeable capsule bodies and plug tablets on drug release in vitro}

Fig. 3 displays the drug release curves of the Cur-SMEDDS-CABs (Fig. 1b), Cur-SMEDDS-CABs in the impermeable capsule bodies without plug tablets and caps (Fig. 1d), and CurSMEDDS-CABs in the impermeable capsule bodies with plug tablets (Fig. 1e) in PBS 6.8.

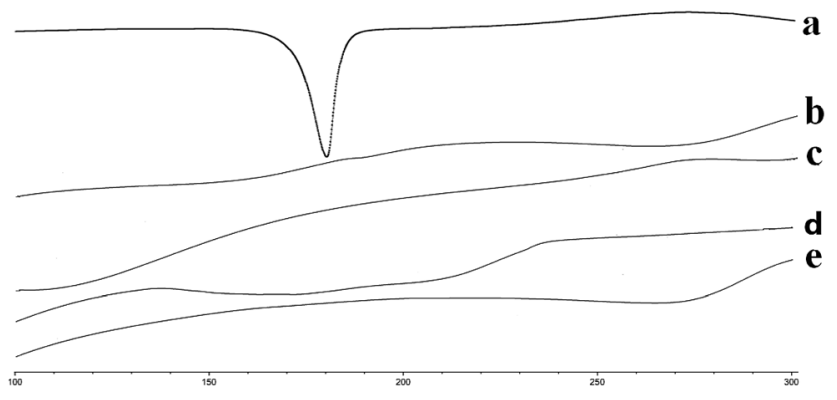

Fig. 2 DSC thermograms of (a) Cur, (b) blank SMEDDS, (c) blank beads, (d) Cur-SMEDDS, and (e) Cur-SMEDDS-CABs. 


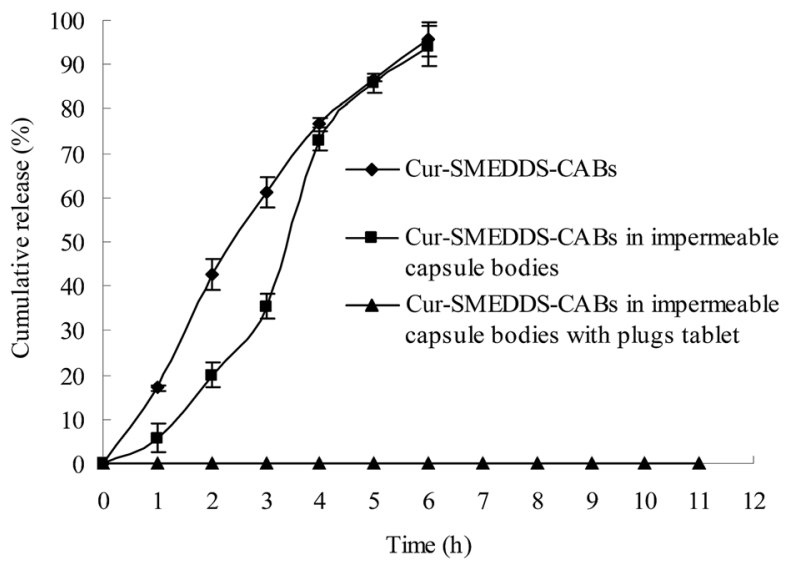

Fig. 3 Effects of impermeable capsule bodies and plug tablet on drug release in vitro $(n=3)$.

When incorporated into the alginate beads, the Cur attained a sustained-release property. As shown in Fig. 3, the CurSMEDDS-CABs slowly released the Cur within $6 \mathrm{~h}$. When the Cur-SMEDDS-CABs were placed in the impermeable bodies, the initial drug release decreased, but over $90 \%$ of the drug was still released after $6 \mathrm{~h}$, indicating that the protection of the impermeable bodies had little effect on the drug release. However, the Cur-SMEDDS-CABs in the impermeable capsule bodies with plug tablets did not release the drug because the KG plug tablet could not be degraded by PBS 6.8 .

\section{Effect of different concentrations of $\boldsymbol{\beta}$-mannase on the lag time of drug release from the plug capsule}

In this study, a $\beta$-mannase solution was used to simulate the fluid in the colon because KG can be specifically degraded by $\beta$-mannase. The effects of different concentrations of $\beta$-mannase on the lag time of drug release from the plug capsule were studied. As shown in Fig. $4,0.7 \%$ and $0.5 \% \beta$-mannase solution accelerated the erosion of the plug tablet and shortened the lag time of the

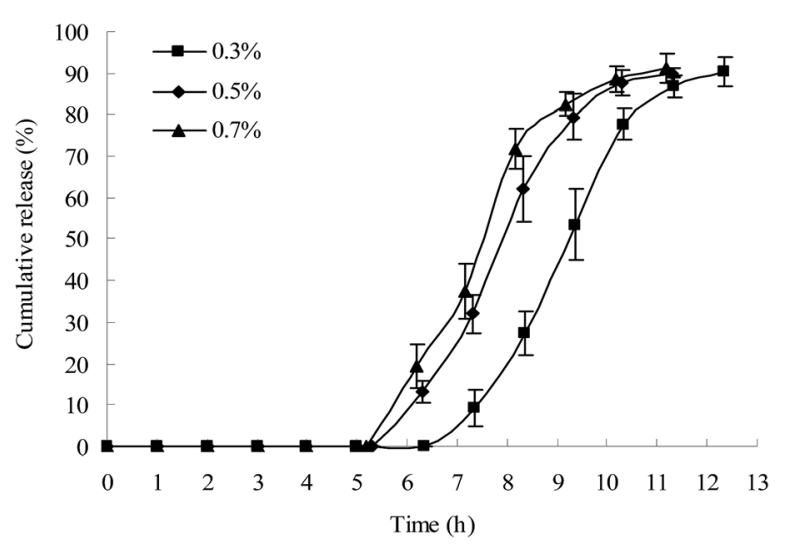

Fig. 4 Effect of $\beta$-mannase concentration on the lag time of drug release from the plug capsule (HPMC =E50-LV; KG/Lac/HPMC = $5: 4: 1, w / w / w ; n=3)$. The release study was first performed in $\mathrm{HCl}$ solution with a pH of 1.2 for $2 \mathrm{~h}$, in PBS 6.8 for $3 \mathrm{~h}$, and then in different concentrations of $\beta$-mannase in acetic acid-sodium acetate buffer solution with a $\mathrm{pH}$ of 6.0 .

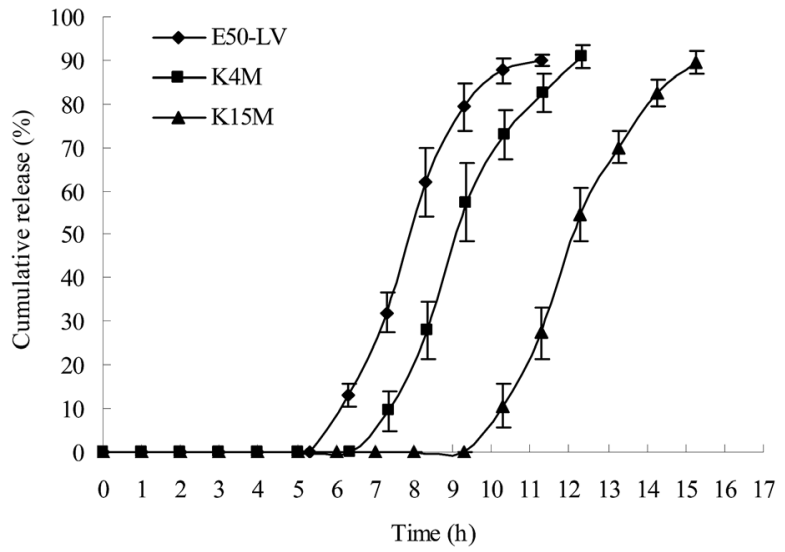

Fig. 5 Effects of different types of HPMC on the lag time of drug release from the plug capsule (KG/Lac/HPMC $=5: 4: 1, \mathrm{w} / \mathrm{w} / \mathrm{w}, n=$ 3). The investigation on drug release was performed in $\mathrm{HCl}$ solution with a pH of 1.2 for $2 \mathrm{~h}$, PBS 6.8 for $3 \mathrm{~h}$, and $0.5 \% \beta$-mannase in acetic acid-sodium acetate buffer solution with a $\mathrm{pH}$ of 6.0 for the rest of the observation period.

drug release. However, no significant difference in lag time was observed between the $0.5 \%$ and $0.7 \% \beta$-mannase solutions. In this study, $0.5 \% \beta$-mannase solution was used as the release medium to evaluate the colon-specific characteristic of the capsule.

\section{Effects of different types of HPMC on the lag time of drug release from the plug capsule}

The gastric transit time varies from 15 min to $3 \mathrm{~h} .{ }^{25}$ In this study, the capsule with impermeable capsule body and enteric cap was not dissolved in the gastric fluid; thus, the individual differences in gastric emptying were reduced. The transit time in the small intestine is approximately $3-4 \mathrm{~h}$. Thus, a $5 \mathrm{~h}$ lag time is generally considered as a suitable lag time for colonspecific drug delivery. A lag time of over $6 \mathrm{~h}$ might result in insufficient drug release in the colon.

HPMC with three different viscosity grades (E50-LV, K4M, and $\mathrm{K} 15 \mathrm{M}$ ) were used to prepare the plug tablets. As shown in Fig. 5, as the viscosity of HPMC increased (E50-LV $<\mathrm{K} 4 \mathrm{M}<$ K15M), the strength of the gel increased, and more time was required to degrade the plug tablet in the $\beta$-mannase solution. The capsule with the HPMC plug (E50-LV) attained a suitable lag time for colon-specific drug delivery.

Effects of different ratios of KG/Lac/HPMC on the lag time of drug release from the plug capsule

The plug tablet with KG alone disintegrated within $10 \mathrm{~min}$ in the release medium. HPMC was introduced to increase the viscosity of the plug tablet. However, the plug tablet with KG and HPMC formed a strong gel matrix structure and barely disintegrated. Lac, a soluble compound with a low molecular weight, was added to accelerate the erosion of the plug tablet. The ratio of KG/Lac/HPMC was adjusted to achieve a suitable lag time and to obtain colon-specific characteristics. Fig. 6 shows the effect of the formulation of the plug tablets on the lag time of drug release from the plug capsule. When the content of KG was decreased while the content of Lac was increased, the 


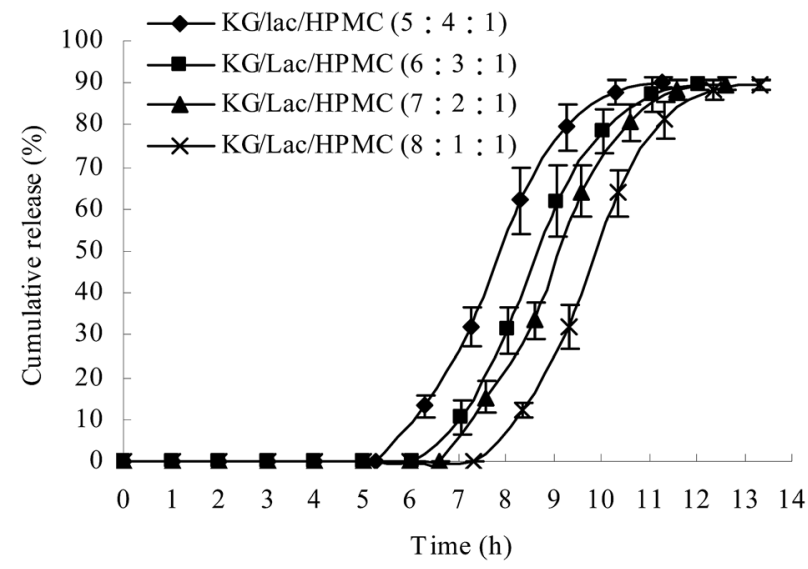

Fig. 6 Effect of the ratio of KG/Lac/HPMC on the lag time of drug release from the plug capsule (HPMC $=E 50-L V, n=3$ ). The drug was first examined in $\mathrm{HCl}$ solution with a pH of 1.2 for $2 \mathrm{~h}$, in PBS 6.8 for $3 \mathrm{~h}$, and finally in $0.5 \% \beta$-mannase in acetic acid-sodium acetate buffer solution with a $\mathrm{pH}$ of 6.0 .

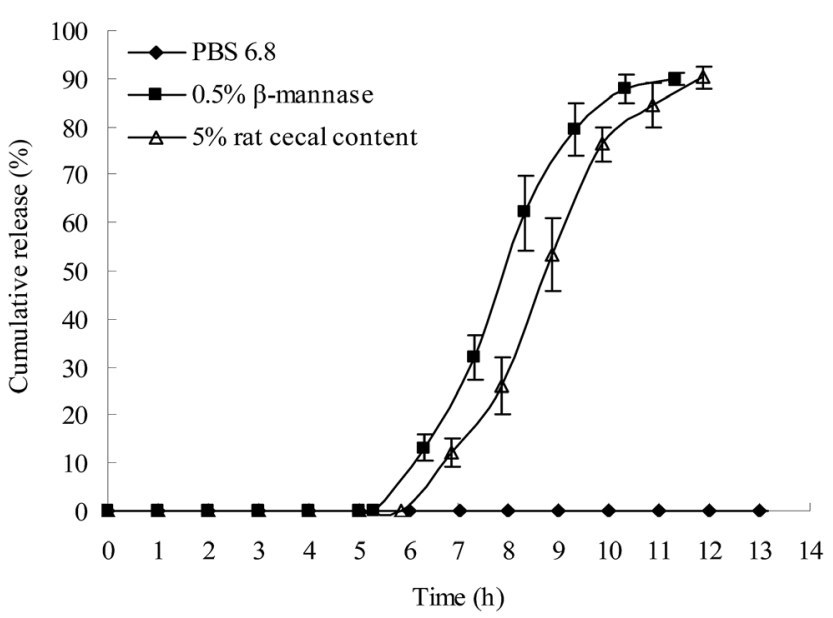

Fig. 7 In vitro release of drug in the simulated colon solution (HPMC $=$ E50-LV; KG/Lac/HPMC $=5: 4: 1, \mathrm{w} / \mathrm{w} / \mathrm{w} ; n=3$ ).

plug obviously expanded during the experiment, and the lag time was shortened. In this study, the KG/Lac/HPMC capsule with a ratio of $5: 4: 1$ achieved a suitable lag time for colonspecific drug delivery.

\section{In vitro release of plug capsules in simulated colon solution}

Apart from the $\beta$-mannase solution, the rat cecal solution was used to evaluate the colon-specific characteristic of the plug capsule. An in vitro release study was conducted in the following release media: (1) $\mathrm{HCl}$ solution with a pH of 1.2 for $2 \mathrm{~h}$ and then PBS 6.8; (2) $\mathrm{HCl}$ solution with a pH of 1.2 for $2 \mathrm{~h}$, PBS 6.8 for $3 \mathrm{~h}$, and then $0.5 \% \beta$-mannase solution; (3) $\mathrm{HCl}$ solution with a $\mathrm{pH}$ of 1.2 for $2 \mathrm{~h}$, PBS 6.8 for $3 \mathrm{~h}$, and then $5 \%$ rat cecal solution.

As shown in Fig. 7 , both the $\beta$-mannase solution and rat cecal solution accelerated the degradation of the plug tablet and shortened the lag time of drug release of the capsule. Compared to the $\beta$-mannase and rat cecal solutions, the plug tablet retained its shape for $13 \mathrm{~h}$ in PBS 6.8, indicating that the KG plug tablet has enzyme-triggered properties. After the lag period, the drug was completely released after $6 \mathrm{~h}$.

\section{Conclusion}

An oral colon-specific drug delivery system based on an impermeable capsule and a KG/Lac/HPMC plug tablet placed in the opening of the capsule body was developed to deliver insoluble drugs to the colon. The insoluble drug, Cur, was made into a liquid SMEDDS to improve its solubility and then incorporated into alginate beads to form the S-SMEDDS. The Cur-SMEDDSCABs demonstrated a sustained-release property and thus could provide longer therapeutic efficacy. After being placed into the impermeable capsule, the Cur-SMEDDS-CABs were protected by the impermeable capsule bodies and thus did not release the drugs until the plug tablet was completely degraded. The KG/Lac/ HPMC plug tablet cannot be hydrolyzed in the upper gastrointestinal tract but can be degraded by the microbial enzymes in the colon. In the small intestine, swelled KG gels formed and blocked the mouth of the capsule. In the colon, the microbial enzymes degraded the KG and disintegrated the plug tablet. Subsequently, the colonic fluid entered the capsule, and the drug exhibited sustained release in the colon. Thus, the drug delivery system possibly has colon-specific characteristics and excellent prospects in clinical applications.

\section{Ethical conduct of research}

The authors state that they have obtained appropriate institutional review board approval or have followed the principles outlined in the Declaration of Helsinki for all human or animal experimental investigations. In addition, for investigations involving human subjects, informed consent has been obtained from the participants involved.

\section{Abbreviations}

$\begin{array}{ll}\text { Cur } & \text { Curcumin } \\ \text { KG } & \text { Konjac glucomannan } \\ \text { Lac } & \text { Lactose } \\ \text { HPMC } & \text { Hydroxypropyl methylcellulose } \\ \text { SMEDDS } & \text { Self-microemulsifying drug delivery system } \\ \text { S-SMEDDS } & \text { Solid SMEDDS } \\ \text { Cur-SMEDDS } & \text { Cur-loaded SMEDDS } \\ \text { Cur-SMEDDS- } & \text { Cur-loaded SMEDDS incorporated into calcium } \\ \text { CABs } & \text { alginate beads } \\ \text { ALG } & \text { Sodium alginate } \\ \text { DSC } & \text { Differential scanning calorimetry } \\ \text { PBS } 6.8 & \text { Phosphate buffer solution with pH of } 6.8\end{array}$

\section{Acknowledgements}

This project was supported by the Natural Science Foundation Project of CQ CSTC (No. cstc2016jcyjA0068), Scientific and Technological Research Program of Chongqing Municipal 
Education Commission (Grant No. KJ120307), Chongqing Board of Health Project (2013-2-060), and Students' Research and Innovation Experimental Project of Chongqing Medical University (201432, 201244, 201229, 201217).

\section{Notes and references}

1 L. F. Fan, W. He, M. Bai, Q. Du, B. Xiang, Y. Z. Chang and D. Y. Cao, Chem. Pharm. Bull., 2008, 56, 1118-1125.

2 C. Freire, F. Podczeck, F. Veiga and J. Sousa, Drug Dev. Ind. Pharm., 2010, 36, 161-172.

3 I. Krogel and R. Bodmeier, Pharm. Res., 1998, 15, 474-481. 4 I. Krogel and R. Bodmeier, Pharm. Res., 1999, 16, 1424-1429. 5 J. Liu, L. Zhang, Y. Jia, W. Hu, J. Zhang and H. Jiang, Arch. Pharmacal Res., 2012, 35, 1927-1934.

6 S. A. Yehia, A. H. Elshafeey and I. Elsayed, Drug Delivery, 2011, 18, 620-630.

7 D. Patel and K. K. Sawant, Curr. Drug Delivery, 2009, 6, 419424.

8 E. P. Hong, J. Y. Kim, S. H. Kim, K. M. Hwang, C. W. Park, H. J. Lee, D. W. Kim, K. Y. Weon, S. Y. Jeong and E. S. Park, Chem. Pharm. Bull., 2016, 64, 1108-1117.

9 C. Sander and P. Holm, AAPS PharmSciTech, 2009, 10, 13881395.

10 V. Agarwal, A. Siddiqui, H. Ali and S. Nazzal, Int. J. Pharm., 2009, 366, 44-52.

11 Y. Ito, T. Kusawake, M. Ishida, R. Tawa, N. Shibata and K. Takada, J. Controlled Release, 2005, 105, 23-31.
12 S. Dokania and A. K. Joshi, Drug Delivery, 2015, 22, 675-690. 13 T. Yi, J. Wan, H. Xu and X. Yang, Eur. J. Pharm. Biopharm., 2008, 70, 439-444.

14 M. Y. Heo, Z. Z. Piao, T. W. Kim, Q. R. Cao, A. Kim and B. J. Lee, Arch. Pharmacal Res., 2005, 28, 604-611.

15 P. Wang, B. Wang, S. Chung, Y. Wu, S. M. Henning and J. V. Vadgama, RSC Adv., 2014, 4, 35242-35250.

16 D. P. Chauhan, Curr. Pharm. Des., 2002, 8, 1695-1706.

17 D. Prajakta, J. Ratnesh, K. Chandan, S. Suresh, S. Grace, V. Meera and P. Vandana, J. Biomed. Nanotechnol., 2009, 5, 445-455.

18 C. D. Mock, B. C. Jordan and C. Selvam, RSC Adv., 2015, 5, $75575-75588$.

19 B. B. Patel and A. P. Majumdar, Nutr. Cancer, 2009, 61, 842846.

20 W. L. Liu, L. K. Zhang, Y. T. Jia, P. Yuan, C. Y. Wang and J. Liu, Chin. Pharm. J., 2011, 46, 1730-1733.

21 C. Y. Yu, B. C. Yin, W. Zhang, S. X. Cheng, X. Z. Zhang and R. X. Zhuo, Colloids Surf., B, 2009, 68, 245-249.

22 F. Stops, J. T. Fell, J. H. Collett and L. G. Martini, Int. J. Pharm., 2008, 350, 301-311.

23 F. Alvarez-Mancenido, M. Landin and R. Martinez-Pacheco, Eur. J. Pharm. Biopharm., 2008, 69, 573-581.

24 M. Liu, J. Fan, K. Wang and Z. He, Drug Delivery, 2007, 14, 397-402.

25 J. Graff, K. Brinch and J. L. Madsen, Clin. Physiol., 2001, 21, 253-259. 